\title{
"Fairtradization": A performative perspective on fair trade markets and the role of retail settings in their enactment
}

\author{
Robbe Geysmans, Michiel PMM de Krom, Lesley Hustinx ${ }^{1}$ \\ Department of Sociology, Ghent University
}

\begin{abstract}
In line with the Callonian approach in economic sociology, this paper introduces the concept of "fairtradization" to analyze the assemblages of human agents, material devices, and discourses through which the fair trade market is enacted. We argue that the retail setting is a key site for the enactment of particular versions of "fair trade," focusing on a case study of the newly designed world shops in Flanders (Belgium). We reveal that the new shop design -aimed to address particular overflows resulting from the mainstreaming of fair trade- constitutes a multivocal shopping environment that enables four analytically distinct enactments of fair trade shopping. Our analytical approach opens up a more dynamic and complex understanding of fair trade beyond the unidirectional diagnosis of mainstreaming. More generally, it provides support for a radically performative view of consumption markets, pointing to the importance of retail settings as socio-material spaces for their enactment.
\end{abstract}

Keywords: fairtradization, fair trade, world shops, marketization, actor-network theory, mainstreaming

\begin{abstract}
Acknowledgments
This research was supported by research grant G.0967.12 from the Research Foundation Flanders (FWO) to Lesley Hustinx. Michiel P.M.M. de Krom is a postdoctoral fellow at FWO. The authors would like to thank all the respondents for their willing cooperation, in particular the staff and volunteers in the national headquarters and the local world shop who provided indispensable support in gathering the data. All authors contributed equally to this work.
\end{abstract}

\section{Introduction}

It would be difficult for a consumer to find a contemporary supermarket that does not sell fair trade products. Large corporate players have entered the world of fair trade, and the Fairtrade label has become a key device for making these products easily recognizable on supermarket

\footnotetext{
${ }^{1}$ Corresponding author: lesley.hustinx@ugent.be
} 
shelves. There is a widespread academic consensus that this situation represents the "mainstreaming" of fair trade. In contrast to the 1960s and the 1970s, when the fair trade movement was limited to the operations of alternative trade organizations (ATOs), in the last two decades there has been a proliferation of fair trade products in "conventional" market settings (Doherty et al. 2013; Goodman 2010; Lekakis 2012, 2013; Low and Davenport 2005; 2006; Nicholls and Opal 2005; Moore 2004; Raynolds 2009; Taylor 2005).

As argued by Le Velly (2015), the dominant reasoning concerning the mainstreaming of fair trade has a deterministic and binary character. The notion of "mainstreaming" invokes a binary line of reasoning, as it restrains analytical thinking to only two scenarios and draws a sharp contrast between them: A small, movement-oriented form of fair trade versus a large, market-oriented form. Moreover, the notion of mainstreaming incites a deterministic reading of these two scenarios, as it suggests that the market-oriented form of fair trade will ultimately prevail, to the detriment of fair trade's "alternative" origins (see also Raynolds 2009). The word mainstreaming thus ultimately stresses "the degradations that fair trade faces when its actors and rules become more and more similar to those of "conventional trade" (Le Velly 2015, 266), in what has been termed "a process of 're-commoditisation', where the characteristics of the producers are more hidden than unveiled [to consumers] and where the products and producers are made substitutable and placed in head-on competition" (Le Velly $2015,274)$.

The binary and deterministic line of reasoning that the notion of mainstreaming entails is problematic, because it does not sufficiently account for the diversity of the fair trade landscape, which includes initiatives that may "not fit with the aforementioned binary grammar" (Le Velly 2015, 267). Moreover, the determinism of mainstreaming implies a somewhat pessimistic perspective on the future of fair trade, as if it is destined to become a watered-down alternative market. By a priori approaching evolutions in fair trade markets through a mainstreaming lens, little room is provided for a more open, diverse, and dynamic reading of the fair trade landscape. In order to move beyond dichotomous and linear thinking, Le Velly proposes applying Callon's notion of market agencements to the fair trade sector, to enable an analysis of "the great diversity of functioning that can be observed in fair trade chains" $(2015,267)$. In this article, we build on Le Velly's proposed application of Callon, by advancing an innovative conceptual approach in order to explore evolutions within the fair trade market in Flanders (the northern, Dutch-speaking part of Belgium).

The approach advanced by Callon and colleagues represents a radical break from the conventional idea of physically existing and differing market spheres, regimes, and types of 
goods. Callon and colleagues consider the market not as a given structure, but instead as an agencement, which implies that it is enacted by a range of agents and actions (e.g., economists, marketers, consumers, and technical devices). Çalışkan and Callon (2009, 2010) coined the terms economization and marketization to underscore the performed nature of economies and markets: "The construction of action (-ization) into the word implies that the economy is an achievement rather than a starting point or a pre-existing reality that can simply be revealed and acted upon" (Çalışkan and Callon 2009, 370). Inspired by and paraphrasing Çalışkan and Callon (2009), in this article we introduce the concept of "Fairtradization," which considers the processes through which behaviors, organizations, institutions and, more generally, objects are constituted as being "fair trade" (cf. Çalışkan and Callon 2010, 2; see also Çalışkan and Callon 2009; Callon 1998). We argue that this approach enables us to reveal the multiple operations of contemporary fair trade markets that are overlooked when drawing on the deterministic and binary line of thinking that is invoked by the prevailing concept of mainstreaming.

We apply the fairtradization approach to an understudied yet crucial aspect of fair trade markets: A retail setting in which fair trade products are sold. Goodman and Bryant (2014) have recently noted that the literature on alternative economies has "barely just begun to explore in any real detail the fundamentally important 'place' of retail" (Goodman and Bryant 2014, 8). Retail settings nevertheless play a crucial role in contemporary consumer markets, because they form the ultimate point of encounter where consumers and product supply chains meet, and interact and co-enact each other (Dubuisson-Quellier 2007; De Krom and Mol 2010). Following our fairtradization perspective, we consider retail settings not simply as "given structures" that enable the encounter of pre-existing spheres of supply and demand, but rather as sites in which particular versions and valuations of "fair trade" are being performed and thus actively achieved. Studying such performance in retail settings enables us to gain important insights into how contemporary fair trade consumption markets are being shaped.

Recent research has begun to explore how certain places both materially and discursively shape "alternative" markets. For example, Johnston (2008) provides a critical assessment of how a corporate actor frames the citizen-consumer hybrid, and Coles and Crang (2011) demonstrate how the retail space of a London food market shapes specific forms of ethical consumption. In another example, Goodman and Bryant (2014) direct specific attention toward world shops in the UK, highlighting ethical ambiguities emerging in the discourse and operation of these retail settings (as compared with second-hand shops). 
In this article, we build on and expand on these emerging insights by analyzing the changing nature of retail outlets within a transforming fair trade landscape. We do this by studying the development and implementation of a new retail concept by OxfamWereldwinkels, the umbrella organization of world shops in Flanders. These world shops are retail outlets that specialize in selling fair trade products. The Oxfam-Wereldwinkels pioneered fair trade in Belgium in the 1970s and have long dominated the Flemish fair trade market. Recently, however, the world shops have begun to lose ground to supermarkets. In this article, we provide insight into the varying concerns that have emerged through this evolution and analyze how these concerns have informed specific enactments of fair trade in and through the re-designed world shops. Our analysis demonstrates "a greater appreciation of the dynamic relationship between corporate adaptation and social movement innovation" (Johnston et al. 2009, 511; see also Goodman and Sage 2014), by focusing on the boundary work that world shops are performing in order to distinguish themselves from other retail settings and gain and retain relevancy within an expanding market (cf. Dupuis and Gillon 2009; Goodman, Dupuis, and Goodman 2011). The recent development and implementation of the new shop concept in the Flemish world shops offers a suitable case to study "fair trade in the making," and to demonstrate how fairtradization provides an appropriate conceptual lens that allows us to move beyond the analytical constraints of the notion of mainstreaming.

\section{Conceptual framework: Fairtradization}

In this paper, we build on what has been termed the "Callonian approach" in economic sociology (Cochoy, Trompette, and Araujo 2016). The Callonian approach starts off from the recognition that the economy in general is "performed" (through processes of "economization"), as are specific markets in particular ("marketization") (Çalışkan and Callon 2009, 2010). Given the existence of a variety of markets, it is important to consider how a specific one is enacted; in our case a fair trade market (cf. Le Velly 2015). To study how contemporary fair trade markets are achieved or performed, we introduce the concept of "fairtradization." By directing attention to processes of market enactment, the notion of fairtradization emphasizes that the qualities of "fair trade" and of "fair trade markets" are not antecedent to economic actions and processes, but instead are outcomes of them. Drawing on the work of Callon and colleagues, we argue that the notion of fairtradization entails two main analytical foci: First on recurrent processes of "market framing and overflowing," and second 
on "socio-technical assemblages" that enable particular "modes of valuations." We elaborate on these below.

To explain the processes of market performance, Callon draws on the Goffmanian concept of framing. By applying this concept to the world of markets, Callon (1998, 1999) underscores the process through which boundaries are drawn around those elements that are part of a market and those that are not. This process of framing entails disentanglement, as elements must be cut off from other networks to which they belong in order to become entangled in a market transaction. In relation to moral economies, Bryant and Goodman also capture this active boundary-drawing process ably in the concept of "spaces of intention" (Bryant and Goodman 2013; Goodman and Bryant 2014). These spaces "combine discourses and material practices, while linking together far-flung people and places to produce distinctive, if changeable, and always multiple, ways of seeing and doing," which inherently also involves drawing "borders that exclude people and knowledge even as they define new networks and communities of the like-minded" (Bryant and Goodman 2013, 38). Spaces of intention can thus exist only in and through framing processes that distinguish them from other spaces, thereby excluding particular elements (e.g. producers who cannot meet quality demands).

As acknowledged by Callon (1998), framing processes are never complete, since there are bound to be elements that "resist" remaining within or outside of the established frame. Callon terms these elements that defy framing as overflows, and clarifies the meaning of these overflows by drawing an explicit parallel with the notion of economic externalities. These economic externalities refer to effects that are produced through market operations, and impact on actors who are not part of the market frame; and whose costs are accordingly not included in market calculations. Well-known examples include air or water pollution caused by factories, which affect neighboring humans, plants, and animals. Overflows as these are likely to raise specific matters of concern-such as e.g. a community's health in case of air or water pollution. These matters of concern may subsequently be incorporated into a market frame, thus adapting market operations (e.g. Callon 2009; D'Antone and Spencer 2014; Mallard 2016; Wilkinson 2010). It is in this context that Geiger and colleagues (2014) refer to concerned markets.

The above line of reasoning is relevant to the fair trade market, which is a "concerned market" that was established to incorporate specific "matters of concern"-namely the unsatisfactory living and working conditions of producers-in a market frame. These concerns emerged as overflows from the operations of more "conventional" (neoliberal) markets 
(Wilkinson 2010). The Callonian line of reasoning also suggests that as the fair trade landscape continues to evolve (including as a result of processes that are predominantly captured by the term "mainstreaming"), it is likely that new overflows and matters of concern will emerge. These new overflows and concerns may, in turn, inform re-framings in and of fair trade markets. We contend that studying such recursive dynamics of framing and overflowing is central to the study of fairtradization, and that it offers a more dynamic and open approach to market changes than the deterministic pathway embedded in the notion of mainstreaming. These processes of market framing and overflowing are, accordingly, the first analytical focus of our fairtradization approach.

The second analytical focus of the fairtradization approach follows from the observation of Çalışkan and Callon (2009) that values are not inherent to goods, nor dependent on given regimes or exchange systems (i.e. on "regimes of values"). Instead, values are specific to "modes of valuation" (Çalışkan and Callon 2009; 2010) that are enacted in particular socio-technical agencements (STAs) (Callon 2007). The concept of STAs highlights how market agency is distributed among many actors and elements, including human agents, material devices, and discourses (Callon 2007, 2016. See also Le Velly 2015). For example, some authors have directed attention to the performative role of (particularly economic and management) knowledge in shaping market transactions (e.g. Çalışkan and Callon 2009; Cochoy 1998; Mallard 2007). The role of material objects has also been explored in what Cochoy (2007) calls a "sociology of market things" (see also Cochoy and Grandclément-Chaffy 2005; Du Gay 2004; Hagberg 2016). When investigating processes of marketization, and hence of fairtradization, a key empirical task therefore consists of identifying the elements (knowledge, material devices, human agents) that constitute an STA, as well as their dynamic interrelations and their roles in enabling specific modes of valuation of fair trade (Callon 2016; Cochoy, Trompette and Araujo 2016).

In this paper, we demonstrate the conceptual power of the fairtradization approach by applying it to the case of a re-designed fair trade retail setting. This empirical focus is informed by our expectation that retail settings will play an increasingly important role in enabling particular modes of valuation in the contemporary fair trade landscape. Different authors (Lekakis 2013; Le Velly 2015; Raynolds 2009) have argued that processes of fair trade standardization conceal marked differences between various fair trade certification and labeling arrangements, since consumers "can hardly see what happens 'behind the label" (Le Velly 2015, 274). Finding other ways of enacting fair trade in order to establish "consumer attachment to specific products" (Raynolds 2009, 1090) that are characterized by specific 
production and trade practices, is therefore likely to surface as a new matter of concern within the fair trade landscape. Retail settings can play an important role in addressing this concern, given their potential to create distinctions-or to "singularize" products and trade practices (Callon, Meadel and Rabeharisoa 2002; Le Velly 2015; Callon 2016)-within competitive markets (cf. Van Marrewijk and Broos 2012). This is not to say that we expect that retail settings will begin to become radically differentiated from each other: Instead, "imitation and differentiation go hand in hand, for the best way of highlighting difference [...] is to make products [and, we would like to add, retail settings] equal in other respects" (Callon 2016, 26).

As mentioned in the introduction, a limited number of insightful studies have begun to explore how retail settings may contribute to creating specific alternative or ethical markets (cf. Coles and Crang 2011; Goodman and Bryant 2014; Johnston 2008). The role that retail settings play in governing processes of framing and overflowing within these markets, however, remains understudied, as these settings tend to be approached as sites that structure individual agency rather than as structures that are themselves also performed. We therefore address the role of retail settings in enacting markets by adding a twist to the assertion of Le Velly and of Callon that shops are just one of the devices in a particular (fair trade) market STA (Le Velly 2015; Callon 2016). Instead, we consider shops as heterogeneous networks themselves, which can be analyzed as agencements that enable specific modes of valuation, and hence play a crucial role in framing a (fair trade or alternative) market.

\section{Data and methods}

The decision to develop a new retail concept for the world shops in Flanders was made in 2011, and was first implemented in a pilot store in 2012. Most of our data was collected in 2013, a year after this implementation. The data-collection activities centered largely on the first pilot store, which is part of the broader umbrella of Oxfam-Wereldwinkels. This organization unites all (i.e. more than 200) world shops in Flanders and the Brussels Region. In general, a broad base of volunteers is responsible for operating these shops, and the organization has been perceived as a democratic volunteer movement (Geysmans 2016; Huybrechts 2010). Since its first implementation, the new shop concept has been introduced in a growing number of stores, and some of its constituent elements have found their way into most, if not all, Flemish world shops. 
The data on which this paper builds can be categorized into three sources: Primary data from eight in-depth interviews with actors who were involved in the development and/or implementation of the new shop concept, primary data collected during visits to the pilot store, and secondary data from documents gathered throughout the research process. We collected the data in a cyclical manner, beginning with an exploratory interview with a key member of staff, followed by an initial store visit on which further in-depth interviews were built.

Given the focus of our study, we did not systematically gather data on the actual doings and sayings of consumers in relation to the new shop concept, but instead were interested in the knowledge and perceptions about consumers that informed the new shop concept. We therefore focused on respondents who-as "market professionals" (cf. Callon and Muniesa 2005)-were involved in strategically developing and implementing the new shop concept.

We interviewed a coordinating manager and two category managers at the headquarters of Oxfam-Wereldwinkels, and two local employees and a key volunteer in the pilot store. We also interviewed three professional retail designers, who were formally contracted by Oxfam-Wereldwinkels to assist in developing and implementing the new retail concept. Table 1 provides an overview of the eight in-depth interviews. The interviews dealt with the respondents' understanding of the reasons why the new shop concept had been developed, the specific knowledge that had informed the design and implementation of the concept, and the roles that materials/devices and human agents (including the interviewees themselves) played in the design and implementation of it. All the respondents were interviewed once, except for the coordinating manager, who was interviewed on two occasions: Once during an exploratory discussion and the second time after we had gained some initial experience with the new shop concept. With the exception of this exploratory interview, all the interviews were audio recorded and transcribed verbatim, and were coded (open and axial) in NVivo. The interviews were conducted in Dutch, and the extracts used in this paper have been translated by the authors.

\footnotetext{
*** Insert Table 1 about here ***

Table 1. Overview of the interviews
}

In addition to the interviews, we paid several visits to the pilot store during the research period. These varied in length from an entire day to shorter visits, which also includes being in the shop for other purposes (e.g. conducting interviews). During the 
different visits, we gathered an extensive amount of data in the form of photographs (around 500 taken by the first author with a digital camera). These photographs are intended to supply a visual overview of the shop in its entirety as a retail setting, and to visually capture all the individual material market devices that are part of the world shops' STA. We supplemented this visual data with field notes of observations that are difficult to capture in a photograph (e.g. short informal talks with volunteers, or a particular atmosphere created through music and lighting). Some of the photographs are used (with permission) to illustrate our findings.

Secondary data was obtained through the national headquarters and the local pilot store, providing us with minutes from meetings, planning documents, and several studies conducted by various organizations (marketing research agencies and institutes of higher education) in collaboration with and commissioned by staff at the national headquarters. These studies were conducted before, during, and after the development and implementation of the new shop concept, and focused on defining the existing and potential customers of the world shops. The secondary data enabled us to gain insight into the knowledge that had informed the new shop concept's STA.

All the data was collected by the first author, and all the authors were involved in analyzing it. In line with our fairtradization approach, our analytical strategy was twofold. First, we traced the different overflows that were intended to be met by designing and implementing the new shop concept. We did this by coding and analyzing the different matters of concern and goals that, according to the interviewees and secondary data, incited and informed the development of the new shop concept. Second, we analyzed how these overflows and matters of concern informed the actual design and implementation of the new shop concept, by directing our analytical attention to how the new shop concept's STA framed the world shops' fair trade market. More specifically, we scrutinized the different elements that constitute the STA of the shop (knowledge/discourses, materials/devices, human agents), and the modes of valuation that these elements enabled. In the following sections, we discuss the results of our empirical explorations.

\section{Findings}

\section{Matters of concern in re-designing the world shop: Addressing overflows of mainstreaming}

Congruent with an international evolution that has been widely discussed as the "mainstreaming" of fair trade (e.g. Doherty et al. 2013; Lekakis 2013; Low and Davenport 
2005, 2006; Raynolds 2009), supermarkets in Flanders nowadays offer a range of fair trade products to their customers. Aiming to promote fair trade practices in the wider market, Oxfam-Wereldwinkels has actively contributed to introducing fair trade products on the shelves of mainstream supermarkets, for example by separating its world shop network from its product brand Oxfam Fairtrade, to enable this brand to be sold by other retailers (for a more extensive discussion, see Huybrechts 2010). The interviews reveal a degree of satisfaction with this evolution:

Fair trade can be bought more and more in different locations. We are happy about this, because we were partly responsible for facilitating this (coordinating manager)

Nevertheless, the fact that supermarkets were stocking fair trade products also led to newly emerging concerns. Indeed, looking through the analytical lens of fairtradization, our data indicates that from the perspective of an alternative trade organization, the mainstreaming of fair trade has led to new overflows that need to be addressed. The alternative fair trade market's original focus on countering the unfair operations of conventional markets is now conflated with pressing overflows resulting from the expansion of the fair trade market itself. Our data reveals two specific overflows of fair trade mainstreaming that formed the basis for the new shop design.

A first overflow was identified when interviewees indicated that even though supermarkets sell fair trade products, they fail to "sell the story" about the ethical importance of purchasing fair trade produce as a means to contribute to better working and living conditions for producers. Joining with scholarly criticism on supermarket cooptation of fair trade's message (e.g. Doherty et al. 2013; Jaffee 2012; Low and Davenport 2005; Reed 2009), a respondent indicated that:

We consider it important to tell the story, and that people do not just buy the products [but also] learn [...] much more than when they just put an item in their supermarket basket (local employee pilot store)

Interviewees particularly emphasized the need to provide consumers with insight into the producers behind the products in order to "de-fetishize" fair trade commodities (cf. Goodman 2004; Hudson and Hudson 2003): 
We do not only sell a product but also a story with that product. Of course the story is partly told on the product itself, as the packaging tells some of it. But the visibility of the partners [i.e., the producers], and that the partner is given a voice, are things that we consider very important in our store (coordinating manager)

These quotes support the claim that the proliferation of fair trade products in mainstream supermarkets has "compromised the efficacy of fair trade as a tool for ethical consumption" (Le Velly, 2015, 265). Our interviewees indeed argue that successful fair trade is not just about the growth of sales through mainstreaming, but critically depends on informed, reflexive consumer choice. Their key emphasis on in-store story-telling as a distinguishing feature of the world shops vis-à-vis the supermarkets suggests that the agencement of product packages on the shelves of both retail settings can only partially contribute to "equipping consumer cognition" (Cochoy 2007) for genuine fair trade consumption. Indeed, as Cochoy argues, in mainstream supermarkets, the Fairtrade label is often the only "discrete window directly on the surface of products" $(2007,123)$ that directs consumers' attention to the ethics of trade practices. As we examine in further detail below, in an increasingly standardized fair trade landscape, the material environment of retail settings performs a key role in market processes of differentiation and "singularization" vis-à-vis the main competitors (cf. van Marrewijk and Broos 2012). Addressing overflows of conventional markets thus extends to the design of the world shops. This supports the claim that in research on alternative markets, more analytical attention should be paid to the performative role of retail settings (Goodman and Bryant 2014) as retail settings play an important role in enacting and contesting the shape of particular markets.

Conveying the fair trade message, however, was intertwined with a partly related, yet also competing matter of concern. The fact that supermarkets had entered the Flemish fair trade market confronted the world shops with another overflow: It implied that the world shops had begun to lose customers to supermarkets:

By no means everything we sell, but a lot of things, are also sold in supermarkets. So fewer and fewer people are making the effort to come to the world shops, because they can easily buy fair trade products along with their daily groceries (local employee pilot store)

This led to a second, pressing concern for the world shops: 
One of the reasons [for developing the new shop concept] was that [the shops] were no longer commercially satisfactory, and that they no longer had customers or that no one came there to buy anymore. This raised the question of whether and in what way such a store could still be relevant (one of the professional retail designers)

These quotes indicate that as an unintended consequence of the successful expansion of fair trade, world shops were at risk of falling outside the fair trade market frame. This would not only have strong economic repercussions for the organization, but would also entail them losing the ability to "impose their valuations on others and consequently to impact strongly on the distribution of value" (Çalışkan and Callon 2010, 13) in the Flemish fair trade landscape. In order to remain relevant, the world shops need consumers to find their way to them, and to "vote" through their purchases in these shops. These consumer votes not only provide benefits to fair trade producers, but also serve as leverage in negotiating and lobbying activities, in which they represent an "individualized collective action" (Micheletti 2003).

By re-framing its shop concept, the world shops intended to (re-)attract consumers: The management aimed to realize a $40 \%$ increase in sales two years after the implementation of the new shop concept in a specific store. Accordingly, Oxfam-Wereldwinkels commissioned commercial and educational research institutions to conduct studies on the target audiences for the world shops. These studies highlighted that (potential) fair trade consumers were unlikely to value world shops for ethical reasons alone, as they were increasingly looking for pleasant and convenient shopping experiences. Constituting what we could term a "generic" fair trade consumer (cf. Latour 2005, 194-195), these findingstogether with more general marketing knowledge and gut feelings-served as the basis for a critical assessment of the previous shop concept.

The assessment of the world shops through the eyes of the "generic consumer" led to the conclusion that (among other reasons) customers shied away from entering the old world shops due to a high "threshold." In other words, the second overflow of mainstreaming was translated into an "image problem" for the historically rooted niche identity of the shops. Several interviewees who were involved in developing the new shop concept stated that the old shops had been perceived as dark and unstructured places, with a left-wing "hippy" image, unconventional opening hours, intrusive educational information, and "unprofessional" volunteer staff. Overcoming this negative image by developing a store that 
would meet contemporary consumers' preferences was a major concern that shaped the development of the new concept:

For a long time, we have focused on our partners [i.e. producers] in the global South [believing] that if we just place [their products] in our stores, they would sell themselves. But we have noticed that this is no longer the case. That is why we have looked for an external partner [the design agency] that is specialized in developing shop concepts and that can help us to take the consumers' point of view into account (coordinating manager)

In sum, our analysis of the rationalities behind the development of the new shop concept supports the idea of a recursive dynamic of framing and overflowing. From the perspective of an alternative trade organization, the mainstreaming of fair trade led to new overflows and matters of concern, which informed a re-framing of the world shop aimed at overcoming these concerns. Building on the second analytical focus of our fairtradization approach, in the following section we turn our attention to the many elements of the new shop's STA, and the modes of valuation that ensue from their assemblage.

\section{Re-framing the world shops: enacting a multivocal shopping environment}

We were able to identify two partly overlapping yet also contradicting modes of valuation that were key to the renewed agencement of the world shops. Overall, a radical break with the old, high-threshold world shop was aimed for, replacing it with an attractive, low-threshold place for fair trade shopping. Taking the generic consumer as the dominant frame of reference, one central mode of valuation was that fair trade consumption should represent a pleasant and convenient shopping experience, comparable with shopping in conventional retail settings. This involved a careful re-design of both the exterior shop window and the interior retail space, including changes to the selection and presentation of products, based on conventional marketing techniques.

At the same time, differentiation was sought through "telling the story." In a context of mainstreaming, Oxfam-Wereldwinkels considered it even more crucial to provide information. Vis-à-vis regular supermarkets, telling the story clearly was a distinguishing feature to promote "concerned market agency." However, the abundance of educational information available in a typical world shop (Goodman and Bryant, 2014) was considered too intrusive and old-fashioned from the standpoint of the generic consumer. In the new shop 
design, the desire to tell the story is inextricably intertwined with the wish to meet contemporary consumers' preferences. Information therefore has to be provided in an accessible, dynamic, low-threshold way, to avoid scaring off casual consumers by disrupting the pleasure and convenience of the shopping experience. This has mainly been achieved through new informational devices and a redefined role for the volunteer shop staff. As a result, the new shop design still enables a mode of valuation in which the fairness of trade practices is a key criterion, yet in the form of a "gentle re-entanglement" of consumerproducer relations.

In the STA of the new world shop, commercial and ethical modes of valuation thus blend, representing a precarious balancing exercise between on the one hand making the world shop more comparable with mainstream market actors, and on the other, singularizing a particular fair trade message. In what follows, we discuss in more detail the heterogeneous elements of the STA of the new shop design. Our analysis reveals that generic consumer preferences form a central guiding principle that ties different processes of re-framing together and enable multiple-more or less overlapping and sometimes conflicting-enactments of the two central modes of valuation. Instead of one strong singularization, the new world shop offers a multivocal shopping environment that allows for multiple market encounters. We identify four analytically distinct ways in which the two modes of valuation are variably enacted: fairtradization by surprise, fairtradization as business-as-usual, fairtradization as gentle re-entanglement, and fairtradization as customized service.

\section{Fairtradization by surprise}

Re-framing the world shop began outside of the store. When the new shop concept was introduced in the pilot store, this store was moved from the outskirts of the city center to a more central street with many small shops and restaurants. This street is adjacent to a busy public square full of bars, and is located in close proximity to several schools. ${ }^{1}$ To enhance the likelihood that passersby would notice the world shop, the pilot store has a large and strongly lit window, attracting the gaze of casual observers. The role of this storefront thus consists of inviting people to enter the shop.

In the past, we mostly tried to get people into the store by making our story very visible - including in the store window and in our external communications in general [...] Now, we say, "no, let's lower the threshold in our external communications," and our store windows are a form of external communication. 
In our external communications, therefore, let's talk about a broad and attractive product assortment or some interesting activities with a low threshold [...] and once customers have entered the store, we bring them into contact with the story in an easily accessible way (coordinating manager)

To lower the threshold, the pilot shop's front window only gives a hint of the fair trade "story" that Oxfam-Wereldwinkels aims to tell, by featuring a large picture of a smiling woman giving a thumbs-up sign next to the entrance (Figure 1). This smiling woman represents a producer whose products can be bought in the store. The picture signifies an invitation to enter the store, and provides a first gentle encounter with the "other" at the supply side of the trade system.

\section{$* * *[$ Enter Figure 1 about here] $* * *$}

Figure 1. Entrance to the pilot store, with a picture of an invitingly smiling producer. Photograph by Oxfam Wereldwinkels vzw

The inviting character of the store extends to the interior design, where wooden furnishings are used to create an atmosphere that is modern, open, and accessible, but also quite natural. The shop is rectangular, with shelves along the side walls, and tables and displays in the central areas. For a customer entering the store, the low central displays and higher shelves against the wall provide an easy overview of the space. A square sales counter with two cash registers (somewhat reminiscent of a bar) is located in the center of the shop. Figure 2, which was taken at the entrance, provides a general overview of the store.

$* * *[\text { Enter Figure } 2 \text { about here }]^{* * *}$

Figure 2. Overview of the pilot store, which is characterized by an open and spacious design. Photograph by Robbe Geysmans

These observations indicate that the new shop's location, window, and interior space are carefully chosen and designed elements of the STA. In contrast to the old world shop, which was argued to be predominantly focused on self-determined and highly committed consumers, the new shop design on the contrary prioritizes attracting "accidental" consumers.

[The idea was that] maybe we should try to redesign the store, make it more pleasing, so it will be more likely for people to enter the store. And hopefully we 
will have taught them something when they walk out of the door again (local employee pilot store)

We think that with the new shop concept, if we are situated in interesting locations with a beautiful and attractive store, it will be easier to attract random passersby. It is within the store that we can then tell them a little about our story (coordinating manager)

By re-framing the shop as more "accessible" and "attractive" (and thus aiming to address the overflow of the old "high threshold" image of the world shops), the unsuspecting passerby should be lured into the shop, to be caught by surprise and then to discover the world of fair trade almost by accident. This is the first central enactment of fair trade in the new shop design, which we term "fairtradization by surprise." Notwithstanding the unintended and low-threshold character of this mode of fairtradization, the intention to perform in-store storytelling (and hence to address the overflow of the lack of attention paid to the "fair trade story" in a "mainstreaming" fair trade market), forms an essential component of it.

\section{Fairtradization as business-as-usual}

As in regular supermarkets, "inter-objective relationships" (Cochoy 2007) between consumers and market devices play an important role in constituting the STA of the world shop. The store contains various market devices that are "in plain sight" and that "even if not always noticed, nevertheless redefine the skills, activities and identities of consumers" (Cochoy 2007, 111). Many of these devices are intended to meet the generic consumer's quest for a pleasurable and convenient (fair trade) shopping experience. To begin with, unlike the old world shops, the new shop contains a clear product classification system to meet consumer demand for clearly structured retail settings. By clustering different products in categories (such as "breakfast" or "drinks and snacks"), and by signaling where these can be found with the use of banners above the shelves, the new shop concept makes it easy for customers to find the products they are looking for. This enables a convenient shopping experience:

One of the issues that we noticed [...] is that there was no clear structure in the shop. Nowadays, a consumer demands clarity, demands a sort of transparency, and wants to be able to "read a shop," as we say. [The customers] want [...] to 
be able to orient themselves from almost any point in the store (one of the professional retail designers)

The overall goal to lower the threshold of the world shop is here translated into a more functional shop design. Notably, very conventional marketing techniques are applied to provide a clear, easily "readable" shopping environment. This is in line with the observed shift in fair trade marketing from a mere focus on emphasizing production processes, to advertising product qualities and appealing to consumers' broader lifestyles (e.g. Alexander \& Nicholls 2006).

The conventional marketing techniques simultaneously mimic and shape the cognitive processes of consumers (cf. Cochoy 2007) to facilitate a pleasurable and convenient shopping experience, while at the same time "arous[ing] [consumers'] desires, cravings and passions" (Callon 2016, 30). For example, the technique of cross-selling is applied to increase sales. Different types of products, such as handicrafts and foodstuffs, are conjointly presented, suggesting ways to combine them (e.g. presenting drinks together with glasses, ingredients together with kitchen tools). In addition, targeted products are also positioned strategically throughout the store's general layout, encouraging customers to "impulsively" purchase them. A number of interactive devices have also been introduced, such as two touchscreens guiding and assisting customers in finding specific products. These touchscreens are positioned at the wine assortment and the coffee assortment, allowing customers to select several basic parameters (e.g. taste, price, or accompanying dish) that the wine or coffee they are looking for will match. Similar devices, although less interactive, are placed on the shelves themselves, in the form of small vignettes highlighting various characteristics of specific products, including price, country of origin, suggested uses, and whether or not they are organic.

In addition to changes in the presentation of products, the new shop concept also includes changes to the range of products on offer. The pilot store served as a "test case" for three years, during which the commercial success of new products could be assessed. Some of the products that were newly introduced into the pilot store were fair trade condoms and Ben \& Jerry's ice cream. Notably, these products did not necessarily meet all of the strict fair trade standards that the world shops applied at the time of developing the new shop concept. That is to say, during the test phase, composite fair trade food products (consisting of more than one ingredient) could be sold without necessarily adhering to the rule that such products must contain at least $51 \%$ fair trade ingredients. ${ }^{2}$ By relaxing this rule for some of the products in 
the pilot shop, the world shops aimed to increase their sales and offer consumers the convenience of "one-stop-shopping," as supermarkets do:

We did this [test these products] mostly to see how such an assortment performed. So whether you could realize more sales with extra products. It was a bit as though we were trying to offer an even larger assortment, having all fair trade products under one roof. So, a sort of small fair trade supermarket (category manager)

For many years, fair trade goods have been marketed for their high quality (e.g. Alexander and Nicholls 2006; Bryant and Goodman 2013; Goodman 2010; Wright 2004), including in world shops (cf. Goodman and Bryant 2014). The sheer quantity of different fair trade products on sale is now becoming a way for the world shops to position themselves within the market, paradoxically by mimicking the larger retailers and their maximization of choice (cf. Johnston 2008). However, the active boundary work we could discern with regard to the product assortment had its limits. In line with our conceptual framework, modifying the entanglement of particular standards and product categories led to new exclusions (cf. Bryant and Goodman 2013; Goodman and Bryant 2014), including of consumers. While the expansion of the world shop's assortment met the preferences of the "generic" consumer, the introduction of Ben \& Jerry's ice cream (a Unilever product) also excluded some customers from the newly established market frame. The pilot store received several complaints about the fact that a Unilever product was being sold in a world shop, and some customers threatened to never visit the store again. The ice cream was eventually removed from the pilot store's product lines, one year after the opening.

Overall, we can analytically distinguish a second enactment of fair trade that we term "fairtradization as business-as-usual." Indeed, the particular network of elements discussed in this section aims to make the world shop comparable with other (regular) retail settings (cf. Callon, Meadel, and Rabeharisoa 2002; Callon 2016) in order to address the overflow concerning the dwindling sales in the old world shops, which was attributed to their "high threshold" image. This is achieved through the use of fairly conventional marketing techniques, mimicking elements also found within other stores, such as a clear and "easily readable" structure, an accessible location, and a wide and varied product assortment. All these elements are tied to the intention of meeting consumer preferences for pleasure and convenience, which are issues that have been high on the agenda of other retailers for many 
years (e.g. Humphery 1998; Lehtonen and Mäenpää 1997). It would, however, be a mistake to simply denounce this re-framing as a form of "mainstreaming." Instead, it is part of a broader process of active market making, in which multiple fair trade enactments intersect and potentially contradict each other, thereby eliciting new concerns and re-framings as novel "spaces of intention" are being explored, resisted (such as by consumers), refined, and redefined.

\section{Fairtradization as gentle re-entanglement}

Within the pilot store, a range of devices can be found which aim to incorporate the fair trade story into the market frame. Some of these devices take a double role, providing pleasure and convenience, while also subtly telling the story. For example, the banners above the shelvesthat indicate which products can be found in which part of the store-feature an image of two hands presenting a basic ingredient of the products on the shelves. In most cases, these hands are of a dark skin color, suggesting to customers that these are the distant hands that produced the commodities (Figure 3).

$$
\text { *** [Enter figure } 3 \text { about here }]^{* * *}
$$

Figure 3. Banner depicting hands holding coffee beans. The banner brings both a story and a structure into the pilot store. Photograph by Robbe Geysmans

Posters throughout the store portray producers along with quotations attributed to them. Depending on the size of the shop, up to five different posters (known as "hero stories" in the jargon of the new shop concept) can be displayed at the same time. The new shop concept also provides two television screens, on which short video clips are shown without audio. Although the range of clips shown is broad, some videos showcase producers during their work, thus de-fetishizing the commodities sold in the store to some extent (cf. Goodman 2004; Hudson and Hudson 2003).

In contrast to Callon's $(1998 ; 1999)$ emphasis on the need to disentangle goods from their producers in order to enable market transactions, these devices thus appear to "reentangle" consumer-producer relations that remain separate in other markets, and accordingly they can be depicted as "re-entanglement devices." In fact, what we see is that a largely interobjective relationship (customer-material device) is intended to establish an inter-subjective relationship (consumer-producer). Or to use the words of Cochoy, these devices provide the 
STA of the world shop with a "window" that is "aimed at opening consumers" eyes to farming issues in southern countries" (2007, 123). By featuring re-entanglement devices in the world shop, the impact that consumption has upon production should become part of the values attributed to the goods sold there.

At the same time, we note that the story is implemented in the new shop concept in such a way that it provides a "gentle" form of re-entanglement. That is to say, the efforts to establish a re-entanglement should not put off potential customers:

It is not the intention to impose [the story] because that is something we no longer want in our stores: That the story is forced, so to speak, on the customer (coordinating manager)

This implies that the devices used to provide the story should not disrupt the pleasure and convenience of shopping. They offer the story in an accessible manner, often combine it with other messages, and ultimately aim to act according to the assumed preferences of the customer. For example, the posters in the store are placed in strategic locations, where people are expected to "naturally" slow down for a while. The posters provide short statements by smiling producers and convey a positive, non-disruptive message about how the producers benefit from fair trade (e.g. by stating that because of fair trade "our children go to school, have decent clothes, and we have sufficient food on the table"). In some cases, these messages are also interwoven with communications about product quality (e.g. a statement that a particular product is a true "delicacy" or "purely natural"). In this sense, the window that these posters open also reflects back into the store, enabling the valuation of fair trade products as quality products that meet consumers' hedonic preferences.

The television screens provide a similar combination of messages, broadcasting a dynamic loop of clips that show producers working in their fields, along with promotions, new products, upcoming activities, and other features. In line with the ambition of the new shop concept to refrain from forcing the story onto consumers when they are not open to it, improvements in the working of this marketing device are considered desirable:

We think that the consumers, the shoppers of today, are actually tired of always just having to watch a short video, having it shoved down their throats. No, they actually want information that interests them. And that is very important. But it is 
a much more expensive application, which certainly could not be realized at the moment (one of the professional retail designers)

In some ways, the new shop concept also hinders a very thorough "story-telling." The efforts of the new shop concept to entice more impulse purchases (see above) are clearly at odds with efforts aimed at enabling consumers to reflect on issues of trade justice. Furthermore, the new shop concept does not prominently feature information on the role that world shops play within the broader fair trade system, or the ways in which the products sold within a world shop ethically differ from other (conventional and fair trade) products. This is striking, given that the world shops often uphold higher standards for their products, frequently maintain closer relations with producers, and in general take a much more activist role in attempts to organize fairer ways of trading compared with other retailers. In this sense, it seems to be at odds with the idea of re-framing the fair trade market in such a way that the overflow of the lack of storytelling is re-embedded in the market frame. More specifically, it seems as if the new shop concept has missed an opportunity to further "singularize" or distinguish its position in a growing fair trade landscape, which it could have achieved by providing more information on its distinct role in constituting the fair trade landscape.

Aside from the fact that much of the visual and textual narratives found in the store may be subjected to the well-elaborated critique of presenting a romanticized commodification of the distant other (cf. Johnston 2002; Varul 2008; Wright 2004), we want to emphasize that in this case, the "new" world shop forms a place for gentle re-entanglement. This is the third central enactment of fair trade in the STA of the new shop design. "Gentle" then refers to the fact that the story is told in such a way that it does not run against customers' expectations of a pleasant and convenient shopping experience, and remains on a relatively superficial level when it comes to more critical reflections on differences between trade practices within and outside the current fair trade landscape.

\section{Fairtradization as customized service}

Lastly, the new shop concept involves a rethinking of the role of the volunteer shop staff who have always been part and parcel of the world shops in Flanders. Here, a fundamental difference exists between the agencement of a supermarket and of a world shop in enacting fair trade. In line with Cochoy (2007), in a supermarket, fair trade products are put on the shelves by invisible "supermarket gardeners," who mainly operate outside the opening hours. 
In contrast to the merely inter-objective relationships that thus dominate supermarket settings (Cochoy 2007), the volunteer staff in the world shop add inter-subjective relationships (between consumers and volunteers) to the fair trade shopping experience. In particular, it was expected that two volunteers would be present in the pilot store at all times:

One of the two volunteers is actually responsible for the cash register. The other volunteer should be more concerned with customers, insofar as this is possible, thus being able to provide some service to the customer (coordinating manager)

In addition to the unavoidable role of cashier or shop manager, the volunteers were attributed two scripted roles (cf. van Marrewijk and Broos 2012) corresponding to the two dominant modes of valuation in the new world shop. On the one hand, volunteers have to provide customers with a pleasant shopping experience, service accordingly centered on being hospitable and responsive to consumers:

For example, if someone enters [the store], you say "hello." In the past, volunteers might not have reacted, or they might have been reading. So [as a volunteer] you are open to questions; you don't stay sitting in a corner, the second volunteer should really walk around. Those sort of things (key volunteer)

On the other hand, the volunteers are also supposed to be able to provide educational information to customers. With this role, the volunteer shop staff are embedded in the enactment of in-store storytelling, along with the material informational devices. The view discussed above, of customers who do not wish to have information "shoved down their throats," is consequently also reflected in the particular role of the volunteers as information providers:

You also have to make sure that you do not scare customers away, of course. If customers always come in and feel like they are going to be addressed immediately and receive lots of information, which they are not open to at all [...] that shouldn't happen. They [the volunteers] have to sense it correctly (local employee pilot store)

By providing information "on demand" this second role joins the first one in an overarching agencement of the world shop as a retail place that offers "customized service." 
Depending on the type of customer-envisioned to range from accidental and hedonic customers to conscientious ethical consumers-the volunteer shop staff need to play different roles (see also Van Marrewijk and Broos 2012). Whereas in the enactment of fair trade as "business-as-usual" the new shop design aims to present a "fair trade supermarket" (see above), here a version of fair trade is performed that is more akin to the highly professional and customized service offered by shop staff in fashion houses and retail stores (cf. Pettinger 2004; van Marrewijk and Broos 2012). The provision of "customized service" can thus be perceived as a reaction to the two overflows of the contemporary fair trade market. First, it reframes the world shop as a pleasant and convenient retail setting, in which the actions of shop staff display care for the customers. Second, by being able to provide educational information to customers, the shop staff should contribute to addressing the concern that the fair trade story gets placed in the background in the current fair trade market. Accordingly, while the role of shop staff in commercial settings such as fashion houses has been identified as an essential component of "branding" (van Marrewijk and Broos 2012), fairtradization as a customized service instead singularizes the world shop vis-à-vis the "depersonalization" of fair trade in supermarket settings (Le Velly 2015), by "gently" extending the intersubjective volunteer/consumer relationship into an intersubjective consumer/producer relationship.

\section{Discussion: Fairtradization in and against the fair trade market}

In this paper, we have built upon the theory of marketization (Çalışkan and Callon 2009, 2010) to understand recent evolutions and operations of fair trade markets. Paraphrasing Çalışkan and Callon, we coined the concept of "fairtradization" to uncover the processes through which behaviors, organizations, institutions, and objects are constituted as being "fair trade" (cf. Çalışkan and Callon 2009, 2010). We demonstrated that this approach is warranted in order to go beyond the binary and linear approach of the mainstreaming debate that has to date dominated the study of fair trade markets and ethical consumption. By applying the fairtradization approach to a case study of the development of a new design for the OxfamWereldwinkels world shops in Flanders, we provided renewed insights into the dynamic and recurrent nature of processes of framing and overflowing. That is to say, we revealed the emergence of specific matters of concern that emerged as "overflows" from existing framings of fair trade. Furthermore, the fairtradization framework enabled us to analyze how these concerns led to a strategic re-framing of the world shops' particular version of fair trade shopping, through the interplay of heterogeneous elements. These elements ranged from 
spatial arrangements (such as the shop window and the structure of the interior retail space), material devices (such as product placement, posters, touchscreens, and the product range), and the scripted roles of the volunteer shop staff.

Does the conceptual framework of fairtradization in the end allow us to think outside the mainstreaming box? On the basis of our case study, we believe it does. On the one hand, the new shop design reflected tensions embedded in the much-discussed discord between movement-oriented fair trade and market-oriented fair trade that is emphasized in analyses according to the notion of mainstreaming (e.g. Lekakis 2012; Low and Davenport 2005; Moore 2004). On the other hand, the conceptual lens of fairtradization opened up new analytical paths to go beyond binary and deterministic analyses that focus on a shifting balance from "alternative" to "mainstream" orientations. Indeed, when looking at the new shop design as a case par excellence of the Callonian inspired idea of "fair trade in the making," it became clear that a fair trade market can no longer be understood by taking fixed regimes of values or given systems of exchange as points of analytical reference. Rather than representing a conflict between the distinct circuits of "movement" and "market," the new shop design was a response to a new cycle of framing and overflowing that had resulted from changes in the fair trade landscape, which were partly inspired by actions of the world shops in the first place.

Through our new analytical focus, we revealed a much more ambiguous process of boundary work. The increasingly complex state of the "mainstreamed" fair trade landscape (Le Velly 2015; Raynolds 2009) has resulted in a state of affairs in which alternative trade organizations are not only positioning themselves "in and against the market" (Barrat-Brown 1993) but also "in and against the fair trade market." We could identify two key matters of concern that emerged in response to the "mainstreaming" fair trade market, and which formed the basis for the enactment of fair trade in the new shop design. On the one hand, alternative fair trade organizations were considered old fashioned. Attracting customers to the shop warranted a rethinking and reframing of the world shop from the perspective of the "generic consumer." This resulted in design interventions to moderate the "radical movement" image of the world shop, thus making this particular version of a fair trade market more comparable with the mainstream version of fair trade in supermarkets. On the other hand, mainstreaming tendencies had led to a standardization and decreased agency of fair trade products and labels: These elements had become increasingly "mute" on the shelves of the supermarkets (Ballet and Carimentrand 2010), or in other words, the "window" on the trade chain had turned opaque. Acting against this devalued version of the fair trade market, the new shop design 
aimed to singularize through in-store storytelling. The enactment of an "informed" or "concerned" version of a fair trade market, however, also had to acknowledge the preferences of the "generic consumer," which led to a non-intrusive or gentle re-entanglement of consumer-producer relations.

A critical observer could derive from these observations that a version of fair trade predominantly aimed at pleasing the "generic consumer" boils down to a fairly conventional story of ordinary fair trade marketing to increase sales; aligning perfectly with the existing claim that mainstreaming signifies a gradual degradation of the fair trade system. This might then raise questions concerning the potential of fair trade to challenge the hegemony of neoliberalist market powers (cf. Johnston 2002). In response, we point to the second analytical focus of the fairtradization approach: For a profound insight into ongoing processes of fair trade market making, it is indispensable to study how prevailing "matters of concern" are translated into specific socio-technical agencements. Through an iterative process of framing and overflowing, fair trade market enactments can adapt to certain pressures from other (here, more dominant) markets and thus conduct boundary work to distinguish (or, in theoretical terms, "singularize") themselves from these other markets. This process of framing and overflowing and boundary-work is a recurrent dynamic, which might induce certain ambiguities, but these should not be perceived as binary extremes, one of which will eventually prevail over the other.

By analyzing the STA of the new shop design, we are able to show that taking the "generic consumer" as a key frame of reference does not simply imply surrendering to the mainstreaming of fair trade. Instead, the combination of the wish to attract more customers to the store and to impart to them the world shop's fair trade story informed an STA for the shop in which at least four analytically distinct enactments of fair trade shopping are enabled. Through these analytically distinct, yet in practice interwoven, versions of fair trade shopping, the new design of the store did not simply cater to the wishes of the "mainstream consumer," but allowed for multiple, more or less "alternative" enactments of fair trade shopping, the actual enactment of which depended on the interplay between the shop's STA and consumers' preferences and behaviors. Ultimately, we argue that the STA of the new world shop transferred the "boundary work" to the individual consumer in her or his instantaneous consumption practice. It is this argument which runs as a thread throughout the different enactments encountered within the world shops.

Our analysis of the dynamic of framing and overflowing that informed the new STA of the world shop raises questions about future dynamics in the fair trade market. Instead of a 
conflict between fundamentally distinct alternative and mainstream versions of fair trade, we have seen a co-evolution of fair trade retailing practices by the world shops and by supermarkets. This warrants the question of whether supermarkets are likely to appropriate the re-framing of fair trade as carried out in the world shops. Since the world shops predominantly aim to distinguish themselves through providing a story, but in the form of a relatively gentle re-entanglement, why then would supermarkets not come to similar ways of working if they observe that world shops succeed in attracting consumers? In particular, the material informational devices that the world shop uses to tell its story could easily be introduced in supermarket settings: It takes relatively little investment to design posters with short producer quotes and smiling producers, or put a television screen alongside shelves, showing short clips of farmers working in a field. Hence, a new recursive dynamic of framing and overflowing may well be at hand, in which world shops may need to re-think once again their role and position in the fair trade landscape, and in promoting fair trade practices.

This clearly offers interesting areas for future research, which should take the newly emerging overflows and matters of concern into account. Moreover, the fairtradization approach could provide important insights when applied to cases beyond the world of retail. It would, for example, be interesting to study the dynamics of fair trade labeling from a fairtradization approach, or the challenges facing producer organizations. Lastly, given our finding that consumers are ascribed a central role in enacting particular modes of fair trade valuation through their in-store purchasing practices, a key topic for further research would be consumer involvement in constituting fair trade.

\section{Conclusion}

We conclude by reflecting on the implications of our conceptual efforts and empirical findings for the wider study of consumption markets and cultures. Our analysis first and foremost provides support for a radically performative view on consumption markets. We advanced our case study of the new shop concept as a current example of active and dynamic "fair trade framing," and studied the re-designing process as an example of active boundary work in the context of a "mainstreaming" fair trade market. Our conceptual focus on recurrent processes of framing and overflowing-and on how these processes inform redesigns of market STAs-might not only prove useful for understanding boundary work in fair trade markets, but also in other alternative markets that are confronted with similar issues of change. Because the dichotomous reasoning offered by the concept of mainstreaming proves 
to be an insufficient framework to capture the full complexity of such changes, "fairtradization" offers a blueprint to study comparable evolutions in other alternative markets, such as the conventionalization of markets for organic and/or local produce.

On the basis of our empirical analysis, we show that the operations of valuation of fair trade products are ongoing and are actually transferred to the situated shopping practice. Consumption markets are continuously performed in the mundane encounters between consumers and retail settings, where different "modes of valuation" are co-articulated and enacted in multiple ways. Our findings are therefore also in line with emerging scholarship on the importance of retail settings as social-material spaces for enacting ethically concerned markets. Although the Callonian perspective places a great deal of emphasis on the "good" as a platform for specific market encounters (Callon 2016), we argue that more systematic attention should be paid to the agencement of the retail place as a whole: By providing a "story," the world shops in fact "use the material environment of retail stores to distinguish themselves from their competitors" (Van Marrewijk and Broos 2012, 374), thus reflecting recent tendencies in research on consumer culture to focus on the socio-material and spatial dimensions of consumption.

\section{Notes}

1. While it may not be possible to re-locate every world shop in which the new concept will be introduced, location is an element that is considered for any store that might incorporate the concept.

2. Since the implementation of the new shop concept, a discussion on this standard has ensued, which has resulted in a partial relaxation of the strict standard.

\section{References}

Alexander, Andrew, and Alex Nicholls. 2006. "Rediscovering Consumer-Producer Involvement: A Network Perspective on Fair Trade Marketing." European Journal of Marketing 40 (11-12): 1236-1253. doi: 10.1108/03090560610702795.

Ballet, Jérôme, and Aurélie Carimentrand. 2010. "Fair Trade and the Depersonalization of Ethics." Journal of Business Ethics 92 (2):317-330. doi: 10.1007/s10551-010-0576-0.

Barratt-Brown, Michael. 1993. Fair trade: Reform and Realities in the International Trading System. London: Zed Books. 
Bryant, Raymond, and Michael K Goodman. 2013. "Peopling the Practices of Sustainable Consumption: Eco-chic and the Limits to the Spaces of Intention." In Green Consumption: The Global Rise of Eco-Chic, edited by Bart Barendregt and Rivke Jaffe, 37-55. London: Bloomsbury Academic.

Çalışkan, Koray, and Michel Callon. 2009. "Economization, Part 1: Shifting Attention from the Economy towards Processes of Economization." Economy and Society 38 (3): 369398. doi: 10.1080/03085140903020580.

Çalışkan, Koray, and Michel Callon. 2010. "Economization, Part 2: A Research Programme for the Study of Markets." Economy and Society 39 (1): 1-32. doi: $10.1080 / 03085140903424519$.

Callon, Michel. 1998. "An Essay on Framing and Overflowing: Economic Externalities Revisited by Sociology." The Sociological Review 46 (1): 244-269. doi: 10.1111/j.1467-954X.1998.tb03477.x.

Callon, Michel. 1999. "Actor-Network Theory - The Market Test." In Actor Network Theory and After, edited by John Law and John Hassard, 181-195. Oxford: Blackwell.

Callon, Michel. 2007. "What Does It Mean to Say that Economics is Performative?" In Do Economists Make Markets? On the Performativity of Economics, edited by Donald MacKenzie, Fabian Muniesa and Lucia Siu, 311-357. Princeton: Princeton University Press.

Callon, Michel. 2009. "Civilizing Markets: Carbon Trading Between In Vitro and In Vivo Experiments." Accounting, Organizations and Society 34 (3-4):535-548. doi: http://dx.doi.org/10.1016/j.aos.2008.04.003.

Callon, Michel. 2016. "Revisiting Marketization: From Interface-Markets to MarketAgencements." Consumption Markets \& Culture no. 19 (1):17-37. doi: 10.1080/10253866.2015.1067002.

Callon, Michel, Cécile Méadel, and Vololona Rabeharisoa. 2002. "The Economy of Qualities." Economy and Society 31 (2):194-217. doi: 10.1080/03085140220123126.

Callon, Michel, and Fabian Muniesa. 2005. "Peripheral Vision: Economic Markets as Calculative Collective Devices." Organization Studies 26 (8):1229-1250. doi: $10.1177 / 0170840605056393$.

Cochoy, Franck. 1998. "The Contribution of Social Sciences to the Construction of Markets: The Case of Marketing." In The laws of the Markets, edited by Michel Callon, 194221. Oxford: Blackwell. 
Cochoy, Franck. 2007. "A Sociology of Market-Things: on Tending the Garden of Choices in Mass Retailing." In Market Devices, edited by Michel Callon, Yuval Millo and Fabian Muniesa, 109-130. Malden: Blackwell Publishing.

Cochoy, Franck, and Catherine Grandclément-Chaffy. 2005. "Publicizing Goldilocks' Choice at the Supermarket-The political Work of Shopping Packs, Carts and Talk." In Making Things Public. Atmospheres of Democracy, edited by Bruno Latour and Peter Weibel, 645-660. Cambridge: MIT Press.

Cochoy, Franck, Pascale Trompette, and Luis Araujo. 2016. "From Market Agencements to Market Agencing: an Introduction." Consumption Markets \& Culture 19 (1):3-16. doi: 10.1080/10253866.2015.1096066.

Coles, Benjamin, and Philip Crang. 2011. "Placing Alternative Consumption: Commodity Fetishism in Borough Fine Foods Market, London." In Ethical Consumption: A Critical Introduction, edited by Tania Lewis and Emily Potter. Abingdon: Routledge.

D'Antone, Simona, and Robert Spencer. 2014. "Concerns and Marketization: the Case of Sustainable Palm Oil." In Concerned Markets: Economic Ordering for Multiple Values, edited by Susi Geiger, Debbie Harrison, Hans Kjellberg and Alexandre Mallard, 72-101. Cheltenham: Edward Elgar.

De Krom, Michiel .P.M.M. and Arthur P.J. Mol (2010) "Food Risks and Consumer Trust. Avian Influenza and the Knowing and Non-Knowing on UK Shopping Floors." Appetite 55 (3): 671-678.

Doherty, Bob, Iain A. Davies, and Sophi Tranchell. 2013. "Where Now for Fair Trade?" Business History 55 (2): 161-189. doi: 10.1080/00076791.2012.692083.

Dubuisson-Quellier, Sophie. 2007. "The Shop as Market Space: The Commercial Qualities of Retail Architecture." In Boutiques and Other Retail Spaces: The Architecture of Seduction, edited by David Vernet and Leontine De Wit, 16-33. Abingdon: Routledge.

Dupuis, E. Melanie, and Sean Gillon. 2009. "Alternative Modes of Governance: Organic as Civic Engagement." Agriculture and Human Values 26 (1): 43-56. doi: 10.1007/s10460-008-9180-7.

Du Gay, Paul. 2004. "Self-Service: Retail, Shopping and Personhood." Consumption Markets \& Culture 7 (2):149-163. doi: 10.1080/1025386042000246205.

Geysmans, Robbe. 2016. "The Evolution of the Discourse of a Belgian Fair Trade Organization: A Two-Dimensional History." Social Enterprise Journal 12 (1): 61-77. doi: doi:10.1108/SEJ-10-2014-0040. 
Geiger, Susi, Debbie Harrison, Hans Kjellberg, and Alexandre Mallard. 2014. "Being Concerned about Markets." In Concerned Markets: Economic Ordering for Multiple Values, edited by Susi Geiger, Debbie Harrison, Hans Kjellberg and Alexandre Mallard, 1-18. Cheltenham: Edward Elgar.

Goodman, Michael K. 2004. "Reading Fair Trade: Political Ecological Imaginary and the Moral Economy of Fair Trade Foods." Political Geography 23 (7):891-915. doi: http://dx.doi.org/10.1016/j.polgeo.2004.05.013.

Goodman, Michael K. 2010. "The Mirror of Consumption: Celebritization, Developmental Consumption and the Shifting Cultural Politics of Fair Trade." Geoforum 41 (1): 104116. doi: http://dx.doi.org/10.1016/j.geoforum.2009.08.003.

Goodman, David, Melanie E. Dupuis, and Michael K. Goodman. 2011. Alternative Food Networks: Knowledge, Practice, and Politics. Abingdon: Routledge.

Goodman, Michael K, and Raymond Bryant. 2014. "Placing the Practices of Alternative Economic Geographies: Alternative Retail, the Spaces of Intention and Ethical Ambiguities." In Alternative Economies and Spaces, edited by Hans-Martin Zademach and Sebastian Hillebrand. Bielefeld: Transcript.

Goodman, Michael K., and Colin Sage. 2014. "Food Transgressions: Ethics, Governance and Geographies." In Food Transgressions: Making Sense of Contemporary Food Politics 1-14. Aldershot: Ashgate.

Hagberg, Johan. 2016. "Agencing Practices: A Historical Exploration of Shopping Bags." Consumption Markets \& Culture $19 \quad$ (1): 111-132. doi: 10.1080/10253866.2015.1067200.

Hudson, Ian, and Mark Hudson. 2003. "Removing the Veil?: Commodity Fetishism, Fair Trade, and the Environment." Organization \& Environment 16 (4):413-430. doi: $10.1177 / 1086026603258926$.

Humphery, Kim. 1998. Shelf Life: Supermarkets and the Changing Cultures of Consumption. Cambridge: Cambridge University Press.

Huybrechts, Benjamin. 2010. "Fair Trade Organizations in Belgium: Unity in Diversity?" Journal of Business Ethics 92 (0): 217-240.

Jaffee, Daniel. 2012. "Weak Coffee: Certification and Co-Optation in the Fair Trade Movement." Social Problems 59 (1): 94-116. doi: 10.1525/sp.2012.59.1.94.

Johnston, Josée. 2002. "Consuming Social Justice: Fair Trade Shopping and Alternative Development." In Protest and Globalisation: Prospects for Transnational Solidarity, edited by James Goodman, 38-56. Annandale: Pluto Press. 
Johnston, Josée. 2008. "The Citizen-Consumer Hybrid: Ideological Tensions and the Case of Whole Foods Market." Theory and Society 37 (3): 229-270.

Johnston, Josée, Andrew Biro, and Norah MacKendrick. 2009. "Lost in the Supermarket: The Corporate-Organic Foodscape and the Struggle for Food Democracy." Antipode 41: 509-532.

Latour, Bruno. 2005. Reassembling the Social: An Introduction to Actor-Network-Theory. Oxford: Oxford University Press.

Lehtonen, Turo-Kimmo, and Pasi Mäenpää. 1997. "Shopping in the East Centre Mall." In The Shopping Experience, edited by Pasi Falk and Colin Campbell, 136-165. London: Sage.

Le Velly, Ronan. 2015. "Fair Trade and Mainstreaming." In Handbook of Research on Fair Trade, edited by Laura T. Raynolds and Elizabeth A. Bennett, 265-281. Cheltenham: Edward Elgar.

Lekakis, Eleftheria J. 2012. "Will the Fair trade Revolution be Marketised? Commodification, Decommodification and the Political Intensity of Consumer Politics." Culture and Organization 18 (5):345-358. doi: 10.1080/14759551.2012.728392.

Lekakis, Eleftheria J. 2013. Coffee Activism and the Politics of Fair Trade and Ethical Consumption in the Global North. Hampshire: Palgrave MacMillan.

Low, William, and Eileen Davenport. 2005. "Has the Medium (Roast) Become the Message? The Ethics of Marketing Fair Trade in the Mainstream." International Marketing Review 22 (5): 494-511.

Low, William, and Eileen Davenport. 2006. "Mainstreaming Fair Trade: Adoption, Assimilation, Appropriation." Journal of Strategic Marketing 14 (4): 315-327. doi: 10.1080/09652540600947912.

Mallard, Alexandre. 2007. "Performance Testing: Dissection of a Consumerist Experiment." The Sociological Review 55: 152-172. doi: 10.1111/j.1467-954X.2007.00734.x.

Mallard, Alexandre. 2016. "Concerning Urban Consumption: On the Construction of Market Agencements for Retail Trade." Consumption Markets \& Culture 19 (1): 56-70. doi: 10.1080/10253866.2015.1068170.

Micheletti, Michele. 2003. Political Virtue and Shopping: Individuals, Consumerism, and Collective Action. New York: Palgrave Macmillan.

Moore, Geoff. 2004. "The Fair Trade Movement: Parameters, Issues and Future Research." Journal of Business Ethics 53 (1): 73-86. 
Nicholls, Alex, and Charlotte Opal. 2005. Fair Trade: Market-Driven Ethical Consumption. London: SAGE Publications.

Pettinger, Lynne. 2004. "Brand Culture and Branded Workers: Service Work and Aesthetic Labour in Fashion Retail." Consumption Markets \& Culture 7 (2): 165-184. doi: $10.1080 / 1025386042000246214$.

Raynolds, Laura T. 2009. "Mainstreaming Fair Trade Coffee: From Partnership to Traceability." World Development 37: 1083-1093.

Reed, Darryl. 2009. "What do Corporations Have to Do with Fair Trade? Positive and Normative Analysis from a Value Chain Perspective." Journal of Business Ethics 86 (0): 3-26.

Taylor, Peter Leigh. 2005. "In the Market But Not of It: Fair Trade Coffee and Forest Stewardship Council Certification as Market-Based Social Change." World Development 33 (1): 129-147. doi: http://dx.doi.org/10.1016/j.worlddev.2004.07.007.

Van Marrewijk, Alfons, and Maaike Broos. 2012. "Retail Stores as Brands: Performances, Theatre and Space." Consumption Markets \& Culture no. 15 (4):374-391. doi: 10.1080/10253866.2012.659438.

Varul, Matthias. 2008. "Consuming the Campesino: Fair Trade Marketing Between Recognition and Romantic Commodification." Cultural Studies 22 (5): 654-679. doi: 10.1080/09502380802245910.

Wilkinson, John. 2010. "Recognition and Redistribution in the Renegotiation of Rural Space: the Dynamics of Aesthetic and Ethical Critiques." In Consuming Space: Placing Consumption in Perspective, edited by Michael K. Goodman, David Goodman and Michael Redlicft, 97-120. Farnham: Ashgate.

Wright, Caroline. 2004. "Consuming Lives, Consuming Landscapes: Interpreting Advertisements for Cafédirect Coffees." Journal of International Development 16 (5): 665-680. doi: 10.1002/jid.1119. 